\title{
ANÁLISE SOBRE O PROGRAMA TEMPO DE APRENDER NO BRASIL: O DIREITO À ALFABETIZAÇÃO OU A PERFORMATIVIDADE DOCENTE?
}

\author{
Análisis sobre el programa Tiempo de Aprender \\ en Brasil: ¿el derecho a la alfabetización o la \\ performatividad docente?
}

Analysis on the Time to Learn program on Brazil:
the right to literacy or teaching performance?

Lucilene Amarante

Universidade Estadual de Maringá (Brasil)

Correo-e: jpe@ufpr.br

Jani Alves Da Silva Moreira

Universidade Estadual de Maringá (Brasil)

Correo-e: jasmoreira@uem.br

Leonardo Dorneles Gonçalves

Universidade Federal do Rio Grande do Sul (Brasil)

Correo-e: Leonardo.dorneles@ufpel.edu.br

Recibido: 20 de mayo de 2020

Envío a informantes: 14 de junio de 2020

Aceptación definitiva: 29 de agosto de 2020

Resumo: O texto analisa o programa Tempo de Aprender apresentado como uma política para a alfabetização pelo Ministério da Educação do Brasil no ano de 2020. Trata-se dos resultados de uma pesquisa exploratória e de análise documental que analisa os pressupostos teórico-pedagógicos presentes no programa instituído pela Portaria n. ${ }^{\circ}$ 280/2020 (Brasil, 2020), cujo propósito fundamenta-se na delimitação de metas para a 
ANÁLISE SOBRE O PROGRAMA TEMPO DE APRENDER NO BRASIL:

O DIREITO À ALFABETIZAÇÃO OU A PERFORMATIVIDADE DOCENTE?

L. AMARANTE, J. ALVES DA SILVA MOREIRA E L. DORNELES GONÇALVES

área, bem como na performatividade docente para enfrentar os problemas da alfabetização no país. As discussões tangenciam aspectos sobre os limites e possibilidades do programa mediante o problema do analfabetismo no contexto das escolas públicas brasileiras. Os resultados indicam que o programa Tempo de Aprender focaliza a relação das práticas alfabetizadoras docentes com o desempenho dos professores e dos alunos.

Palavras-chave: políticas de alfabetização; Tempo de Aprender; performatividade; alfabetização; Brasil.

Resumen: El texto analiza el programa Tiempo de Aprender, presentado como una política de alfabetización por el Ministerio de la Educación de Brasil en el año de 2020. Se trata de los resultados de una búsqueda exploratoria y de análisis documentales que analiza los presupuestos teóricos y pedagógicos presentes en el programa instituido por la Disposición n. ${ }^{\circ}$ 280/2020 (Brasil, 2020), cuyo propósito se fundamenta en la delimitación de las metas para el área, bien como en la performatividad docente para enfrentar los problemas de la alfabetización en el país. Las discusiones se relacionan con aspectos sobre los límites y posibilidades del programa mediante el problema del analfabetismo en el contexto de los colegios públicos brasileños. Los resultados indican que el programa Tiempo de Aprender enfoca la relación de las prácticas alfabetizadoras docentes con el desarrollo de los profesores y alumnos.

Palabras clave: políticas de alfabetización; Tiempo de Aprender; performatividad; alfabetización; Brasil.

AвsтRAст: This text analysis the program Time to Learn, shown as a policy for literacy by the Brazilian Ministry of Education in 2020.The text presents the results of an exploratory research and document analysis on the theoretical-pedagogical assumptions present in the program established by the Ordinance n. ${ }^{\circ} 280 / 2020$ (Brasil, 2020), whose purpose is based on the setting of goals for the area, as well as on the teaching performance to face the literacy problems in the country. Discussions touch aspects on the limits and possibilities of the program through the problem of illiteracy in Brazilian public schools. Our results point that the program Time to Learn focus on the relationship of the teacher's literacy practices and the performance of teachers and students.

KEY WORDs: literacy policies; Time to Learn: performance; literacy; Brazil.

\section{Introdução}

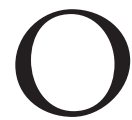

PRESENTE TEXTO se refere a uma análise sobre a atual política para a alfabetização desenvolvida pelo Ministério da Educação (MEC) no Programa Tempo de Aprender, lançado em i9 de fevereiro de 2020 pela Portaria n. ${ }^{\circ}$ 280 (Brasil, 2020), que o definiu como uma Política Nacional da Alfabetização. A metodologia adotada se refere a uma análise documental e bibliográfica, no qual o documento basilar é a Portaria n. ${ }^{\circ}$ 280/2020 (Brasil. MEC, 2020).

Para alcançar o proposto, o texto problematiza e analisa a portaria que institui o programa em questão, a fim de conjecturar quais direcionamentos, concepções e ações são delineadas para as políticas de alfabetização na atual gestão governamen- 
ANÁLISE SOBRE O PROGRAMA TEMPO DE APRENDER NO BRASIL:

O DIREITO À ALFABETIZAÇÃO OU A PERFORMATIVIDADE DOCENTE?

L. AMARANTE, J. ALVES DA SILVA MOREIRA E L. DORNELES GONÇALVES

tal. Na sequência, evidenciam-se aspectos centrais da performatividade exigida aos professores que atuam no ciclo de alfabetização ${ }^{1}$ e que possuem como atribuição a responsabilidade pela alfabetização, na luta pela garantia da efetivação do direito de todo sujeito se tornar letrado. Por fim, o texto examina os limites e as possibilidades que se acentuarão com a implementação do Programa Tempo de Aprender no contexto da alfabetização.

\section{Programa Tempo de Aprender: concepções e propostas}

O Brasil é um país marcado por desigualdades sociais, principalmente, no que se refere ao acesso a uma educação de qualidade a todos e a todas, em especial, o conhecimento do mundo letrado. Dados atuais das avaliações revelam que mais da metade dos alunos brasileiros ainda estão analfabetos em leitura, escrita e matemática (Brasil, 20I8).

Nesse sentido, cabe ao Estado um maior comprometimento em efetivar políticas que atinjam e diminuam os estratos da desigualdade, dentre elas, a alfabetização a todas as crianças na idade certa. Mortatti (20Io, p. 329) conceitua que a alfabetização é «[...] um processo complexo e multifacetado que envolve ações especificamente humanas e, portanto, políticas, caracterizando-se como dever do Estado e um direito constitucional do cidadão», no qual a alfabetização é um dos meios de luta contra a discriminação e as injustiças sociais.

Dada essa importância, diante das intensas mudanças nas políticas educacionais desencadeadas pelo Estado em promover programas de alfabetização no $\mathrm{Brasil}^{2}$, o atual Governo Federal ${ }^{3}$ em 19 de fevereiro de 2020 , instituiu a Portaria n. ${ }^{\circ} 280$ (Brasil, 2020) e lançou o programa Tempo de Aprender pelo Ministério da Educação, o qual dispõe as diretrizes para a alfabetização no Brasil integrando-as, assim, à Política Nacional da Alfabetização. Em específico, o programa focalizará o último ano da educação infantil e o primeiro e segundo ano do ensino fundamental.

Destaca-se que a adesão pelos 26 estados e 5.570 municípios brasileiros ao Programa é facultativa. Todavia, Frade (2019, p. 96) questiona: «[...] entre conseguir mais recursos para formação e materiais didáticos e adotar métodos resultantes do acúmulo pedagógico, que escolha fará o sistema?». Acredita-se, portanto que, dificilmente um ente federado posicionar-se-á contra as políticas que são direcionadas pelo Estado à alfabetização, uma vez que envolve a contrapartida de verbas para formação de pro-

A Resolução CNE/CEB n. o o/20Io, no artigo 30 parágrafo I. ${ }^{\circ}$ estabelece o "ciclo de alfabetização» os três primeiros anos do Ensino Fundamental e conceitua como «[...] bloco pedagógico ou um ciclo sequencial não passível de interrupção, voltado a ampliar a todos os alunos as oportunidades de sistematização e aprofundamento das aprendizagens básicas, imprescindíveis para o prosseguimento dos estudos [...]» (BRASIL, 2OIO).

Programas e ações destinados à alfabetização no Brasil entre as décadas de 20Io e 2020: Plano Nacional de Educação (PNE) 20II-2020 (2OIO); Plano Nacional de Educação (PNE) (2OI4-2024); Pacto Nacional Pela Alfabetização na Idade Certa (2013-2017); Programa Mais Alfabetização (20I8-20I9); PNA Política Nacional da Alfabetização (20I9); Programa Conta pra mim (2019); Programa Tempo de Aprender (2020) (Mortatti, 2013).

Jair Messias Bolsonaro, atualmente sem partido, assumiu a presidência da república no Brasil, em or de janeiro de 2019 . 
ANÁLISE SOBRE O PROGRAMA TEMPO DE APRENDER NO BRASIL:

O DIREITO À ALFABETIZAÇÃO OU A PERFORMATIVIDADE DOCENTE?

L. AMARANTE, J. ALVES DA SILVA MOREIRA E L. DORNELES GONÇALVES

fessores, infraestrutura, recursos didáticos e, ainda, tem a menção à expectativa por resultados positivos, com vistas à promoção do ensino e aprendizagem.

Neste contexto, o programa Tempo de Aprender estabelece que o objetivo principal é «melhorar a qualidade da alfabetização em todas as escolas públicas do Brasil» (Brasil, 2020, p. oI) e no artigo $6 .^{\circ}$ institui outros objetivos:

I - elevar a qualidade do ensino e da aprendizagem no âmbito da alfabetização, da literacia e da numeracia, sobretudo nos anos iniciais do ensino fundamental, por meio de abordagens cientificamente fundamentadas; II - contribuir para a consecução da Meta 5 do Plano Nacional de Educação, de que trata o Anexo à Lei n, ${ }^{\circ} 13.005$, de 20I4; III - assegurar o direito à alfabetização a fim de promover a cidadania e contribuir para o desenvolvimento social e econômico do País; e IV - impactar positivamente a aprendizagem no decorrer de toda a trajetória educacional, em seus diferentes níveis e etapas. (Brasil, 2020, p. O2)

Para atingir tais objetivos, as ações do Tempo de Aprender sustentam-se em quatro eixos que considera de maior prioridade, sendo eles: a formação docente e de gestores; materiais e recursos para professores e alunos; acompanhamento da evolução das aprendizagens dos alunos por meio de avaliações e; valorização dos profissionais da alfabetização.

Um primeiro aspecto a destacar é que o programa no Eixo I reitera a formação docente e dos gestores educacionais.

I - Eixo - Formação continuada de profissionais da alfabetização: a) formação continuada para professores alfabetizadores e para professores da educação infantil; b) formação continuada para gestores escolares das redes públicas de ensino; e c) programa de intercâmbio para formação continuada de professores alfabetizadores. (Brasil, 2020, p. I)

As formações previstas para os profissionais participantes são organizadas sob as formas on-line e presenciais. Porém, as formações presenciais serão ofertadas apenas para alguns profissionais, os quais serão os multiplicadores dos conteúdos e terão como base os fundamentos pautados nas categorias competências e habilidades para alfabetizar as crianças. Como menciona o documento: «[...] proporcionar aos docentes a aquisição de conhecimentos, habilidades e estratégias que os auxiliem a lidar com os desafios postos pelo ciclo de alfabetização» (Brasil, 2020).

Silva e Moreira (2019, p. 78) argumentam que «[...] a focalização no desenvolvimento de competências, as quais atendam às exigências do capital, estão no cerne de muitas deliberações e aprovações de documentos oficiais no Brasil». Assim, os conceitos de habilidades e competências têm sido recorrentes na agenda das políticas educacionais dos planos governamentais desde a década de $1990^{4}$. Possuem estreita relação com a ideologia das competências e Pedagogia das Competências em que a visão econômica e a formação de capital humano prevalecem em detrimento à formação para a apropriação de conhecimentos históricos para a emancipação dos sujeitos, portanto, as autoras enfatizam que são «propostas que desvalorizam a educação tornan-

4 Em especial destacamos que a partir da década de 1990 houve uma expansão à lógica do mercado na educação brasileira, com uma intensa reforma curricular a partir das recomendações de organismos internacionais e nos pressupostos dos quatro pilares da educação, apresentados pelo Relatório Jacques Delors. 
ANÁLISE SOBRE O PROGRAMA TEMPO DE APRENDER NO BRASIL:

O DIREITO À ALFABETIZAÇÃO OU A PERFORMATIVIDADE DOCENTE?

L. AMARANTE, J. ALVES DA SILVA MOREIRA E L. DORNELES GONÇALVES

do-a um mero produto mercadológico não condizente com o seu principal valor de emancipação humana» (Silva e Moreira, 2019, p. I60).

Essa concepção mercadológica está presente nas proposições do programa Tempo de Aprender, no qual por meio da formação ofertada, o professor passa a ser o principal responsável pelos bons ranqueamentos da alfabetização, tendo em vista que, as práticas educativas em salas de aula induzem o alunado a corresponder às exigências de competências e habilidades dos interesses do mundo globalizado. Sobre essa questão, Lenardão e Galuch (2018) argumentam que o espaço escolar reproduz os princípios de uma sociedade dominada pelos interesses traçados pelos grupos dominantes e, por isso, as práticas e formações destinadas aos docentes e discentes apontam para a manutenção de uma sociedade menos crítica e mais produtiva que se fundamenta, principalmente, em argumentações de senso comum:

Esse poderoso instrumento de socialização tem sido alvo de variados modelos formativos que raramente são submetidos ao crivo da crítica teórica, em grande medida porque os agentes fundamentais que ali atuam - os professores - também são formados pelo viés acrítico. (Lenardão e Galuch, 2018, p. 155)

Ao considerar que a aprendizagem ocorre em um processo dialético, pondera-se que não há uma formação significativa quando teoria e prática logram movimentos independentes e desconexos, pois, esta relação é de extrema relevância para que os conhecimentos sejam consolidados e ressignificados junto aos estudantes, com ações mediadoras conscientes e intencionais, portanto, como defende Castanheira (20I4, p. 287 ) «[...] A formação de professores calcada num projeto emancipatório» urge pensar o ensino em uma ação crítica-reflexiva para que, também, os estudantes possam ser emancipados.

No que concerne ao eixo de apoio pedagógico para a alfabetização, evidencia-se que no programa Tempo de Aprender, a centralidade está na reestruturação do livro didático e na ajuda pedagógica que será ofertada aos professores.

II - eixo Apoio pedagógico para a alfabetização: a) sistema on-line com recursos pedagógicos e materiais para suporte à prática de alfabetização; b) recursos financeiros de custeio para assistentes de alfabetização e outras despesas previstas em resolução específica; c) aprimoramento do Programa Nacional do Livro e do Material Didático - PNLD para educação infantil e $\mathrm{I}^{\mathrm{o}}$ e $2^{\circ}$ anos do ensino fundamental. (Brasil, 2020, p. I)

Neste eixo, o programa propõe melhorar a alfabetização com base em evidências científicas e outorga uma solução tecnológica para auxiliar professores na elaboração de planejamento para as aulas (Brasil, 2020). Coloca-se centralidade no trabalho do professor e sua atividade de elaboração das aulas para ensinar e sanar as dificuldades específicas de cada estudante. Do exposto, julga-se que preparar aulas com redução do processo de mediação para uma simples reprodução de experiências e evidências pré-estabelecidas, é desqualificar a função da pesquisa docente como atividade inerente ao trabalho do professor.

O processo alfabetizador firma-se no trabalho que envolve momentos em que o professor pesquisa e planeja, intencionalmente, mediações de interação do aluno com a escrita por meio da reflexão acerca do sistema alfabético, de forma que o aluno se expressará por meio de símbolos, letras, ideias, sentimentos e pensamentos; 
ANÁLISE SOBRE O PROGRAMA TEMPO DE APRENDER NO BRASIL:

O DIREITO À ALFABETIZAÇÃO OU A PERFORMATIVIDADE DOCENTE?

L. AMARANTE, J. ALVES DA SILVA MOREIRA E L. DORNELES GONÇALVES

a escrita passará a ter um significado concreto para cada estudante. Nesse sentido, Smolka (1989, p. 69) assevera que «[...] a alfabetização implica, desde a sua gênese, a constituição de sentidos». Não obstante, por mais que se tenha uma sociedade grafocêntricas, o estudante somente aprende as diferentes linguagens se houver mediações docentes propositalmente planejadas e voltadas para a especificidade de cada aluno.

Concomitante ao direcionamento do trabalho docente, outro aspecto a salientar no prescrito pela Portaria n. ${ }^{\circ}$ 280/2020 é o «[...] aprimoramento do Programa Nacional do Livro e do Material Didático - PNLD para educação infantil e $\mathrm{I}^{\circ}$ e $2^{\circ}$ anos do ensino fundamental» (Brasil, 2020, p. or). Conjectura-se que novos livros serão elaborados de acordo com as diretrizes do Tempo de Aprender, a partir dos seus idealizadores da Secretaria de Alfabetização (Sealf) do MEC, como a solução para a alfabetização, o que poderá deixar de utilizar as fontes a partir dos atuais pesquisadores. Os livros didáticos representam um recurso importante, porém, não o único, para o trabalho de ensino e aprendizagem. Como pontua Saviani $(2007$, p. 136) «[...] os livros didáticos serão o instrumento adequado para a transformação da mensagem científica em mensagem educativa».

Assim, entende-se que, apoio pedagógico, reestruturação do PNLD e recursos para um auxiliar de alfabetização em sala de aula, somente serão exitosos na medida em que as ações docentes promovam aprendizagens para além das diretrizes instituídas pelo Programa. As ações docentes devem ter o fito de desenvolver cognitivamente cada estudante para que, por meio do conhecimento científico, assuma posicionamentos críticos diante das desigualdades e injustiças sociais.

Em relação ao eixo III apresentado no Programa, aprimoramento das avaliações da alfabetização, a portaria determina:

a) aplicação de diagnóstico formativo de fluência em leitura; b) aperfeiçoamento das avaliações do Sistema de Avaliação da Educação Básica - Saeb voltadas à alfabetização; e c) avaliação de impacto do Programa. (Brasil, 2020, p. r. Grifos nossos)

O eixo prescreve como objetivo a «[...] verificação do desempenho em alfabetização dos alunos do $2^{\circ}$ ano do ensino fundamental» (Brasil, 2020). Sendo assim, é possível aferir que, para a efetivação da meta proposta, a prática docente passa a ser influenciada e regulada pelos resultados das avaliações aplicadas à alfabetização pelo Sistema de Avaliação da Educação Básica - SAEB 6 .

Nesta linha, é fundamental que existam discussões sobre a real intencionalidade das avaliações que medem a aprendizagem dos estudantes. As atuais avaliações não consideram o contexto social em que as escolas estão inseridas. Tais avaliações se configuram em um discurso que ignora os demais processos que se fazem presente na escola pública, bem como as condições objetivas de infraestrutura para o funcionamento adequado, formação dos docentes e todo investimento efetivado pelo Estado para uma educação pautada no amplo acesso ao conhecimento histórico.

No que tange ao eixo de valorização dos profissionais da alfabetização, a Portaria n. ${ }^{\circ}$ 280/2020 versa: «IV - eixo Valorização dos profissionais da alfabetização, por meio da instituição de premiação para professores alfabetizadores» (Brasil, 2020, p. I).

Sociedade centrada na escrita. Ver: GadotTi (1982).

6 O Sistema de Avaliação da Educação Básica (SAEB) tem como objetivo realizar um diagnóstico do sistema educacional brasileiro (SCHNEIDER, 20I2). 
ANÁLISE SOBRE O PROGRAMA TEMPO DE APRENDER NO BRASIL:

O DIREITO À ALFABETIZAÇÃO OU A PERFORMATIVIDADE DOCENTE?

L. AMARANTE, J. ALVES DA SILVA MOREIRA E L. DORNELES GONÇALVES

Sobre esse aspecto, cabe ponderar que a valorização de professores está atrelada aos bons resultados que as turmas alcançarem, mais uma vez, desconsideram os diversos contextos culturais e sociais em que os estudantes se inserem e na comunidade as quais pertencem. Filho; Barros e Nunes (2020) observam que muitos programas e políticas implementados pelo Estado, são ofertados de maneira homogênea e descontextualizados das realidades em que se encontram as escolas públicas. Com isso, os autores justificam que conceber uma política unilateralmente é:

[...] desconhecer as realidades sociais diversas da população brasileira enfrentadas por alunos (as) e seus/suas professores (as) cotidianamente, tais como escolas sem banheiros, alunos que remam e caminham quilômetros até suas escolas, muitas vezes sem infraestruturas adequadas, falta de equipamentos e materiais pedagógicos essenciais e violência urbana. Não há melhor incentivo que salários e condições de trabalho dignos! (Filho, Barros e Nunes, 2020, p. 2)

Outro aspecto presente no Programa está na premiação e meritocracia, no qual a estratégia elencada de "premiação de professores alfabetizadores» (Brasil, 2020) remete à recompensa aos professores e incentivo à melhoria de seu desempenho, o que indica a causa do insucesso da alfabetização no Brasil à falta de comprometimento dos professores.

De forma geral, é possível perceber que por meio da proposta do programa Tempo de Aprender (Brasil, 2020), o Estado direciona as escolas públicas a se pautarem em fundamentos de uma educação gerencialista que busca, em sua essência, por meio de uma ótica neoliberal, tornar o sistema educativo mais competente, eficiente, produtivo e de qualidade.

Em específico, compreende-se que a composição dos quatro eixos do programa Tempo de Aprender (Brasil, 2020) sinalizam para uma performatividade docente caracterizada por modelos just in time, capazes de gerenciar objetivos e metas à distância, dinamizando poucos recursos didáticos, sob a pressão tecnológica e externa, que privilegiam as experiências em contextos escolares internacionais profundamente distintos dos contextos brasileiros.

Da mesma forma, a performatividade do professor alfabetizador é induzida por mecanismos de avaliações externas, os quais induzem conteúdos e conformam currículos escolares de formas assimétricas, sem considerar as condições objetivas para o aprendizado. $\mathrm{O}$ estudo nacional de fluência que se apresenta pelo programa «Tempo de Aprender» (Brasil, 2020) sintetiza a concepção de «aferir» níveis, sem que haja a indicação de práticas que possam mensurar as condições para alcançar a fluência desejada.

Por conseguinte, o Tempo de Aprender (Brasil, 2020) expressa um tipo ideal de professor alfabetizador na medida em que estipula premiações por desempenho aos profissionais. Para além da infeliz ironia em relação à situação salarial dos profissionais da educação no Brasil, o que, por si, já seria elemento de crítica radical, o eixo busca fortalecer a indução de mecanismos de mercado à lógica do trabalho docente, no qual concebem o conhecimento e as relações pedagógicas como mercadorias, isto é, o produto originário do trabalho docente, avaliado de acordo com o seu resultado final. 

256
ANÁLISE SOBRE O PROGRAMA TEMPO DE APRENDER NO BRASIL:
O DIREITO À ALFABETIZAÇÃO OU A PERFORMATIVIDADE DOCENTE?
L. AMARANTE, J. ALVES DA SILVA MOREIRA E L. DORNELES GONÇALVES

Entende-se que há, a partir das proposições do Programa, uma incorporação de um modelo docente capaz de traduzir metas em resultados que se condicionam por premiações, mediatizado por instrumentos tecnológicos que articulam o que se deve ensinar ao que será cobrado em avaliações externas. Ajuíza-se que as condições necessárias ao processo de alfabetização estão relegadas e incindem no trabalho docente, na aprendizagem dos estudos e, no limite, ampliam a negação do direito a alfabetização.

\section{Direito à alfabetização versus performatividade docente no âmbito do progra- ma Tempo de Aprender (2020)}

No Brasil, a Constituição Federal (CF) de 1988 em seu artigo 214 inciso I afirma que a erradicação e o combate ao analfabetismo são metas para serem alcançadas, independente da gestão governamental que está à frente da sociedade brasileira. $\mathrm{O}$ direito à educação, instituído no Art. 205 da Constituição Federal (1988), vai além de um direito abstrato, que visa apenas o conhecimento e a aprendizagem escolarizada, mas deve abranger a qualidade da alfabetização em uma ampla formação do sujeito que vive e interage em sociedade.

Cagliari (1989, p. Io) defende a alfabetização como parte do direito à educação, pois, proporciona ao sujeito inserir-se no mundo do conhecimento sistematizado, a partir disso, participar das decisões que dizem respeito à construção de uma sociedade democrática, estar alfabetizado é «[...] condição necessária à participação na sociedade letrada em que vivemos». Mortatti (2019, p. 6) defende que a alfabetização é um dos instrumentos de aquisição do saber que proporciona o «esclarecimento das massas», tornam a leitura e a escrita os fundamentos de uma nova ordem política, econômica e social e, também, fator de modernização para um país.

As políticas voltadas para essa área têm ido à contramão dos conceitos supracitados, por investirem na formação humana sob à lógica do mercado de trabalho, tornando o sujeito, muitas vezes, incapaz de compreender as contradições que o mundo capitalista acarreta sobre o processo educacional e, em particular, na alfabetização. A escola atual tem incorporado as consequências e contradições deste sistema, que se expressa no cotidiano escolar por preconceito, indisciplina, pobreza, violência e evasão escolar. Desta forma, é insuficiente alfabetizar para atingir os melhores resultados, como se os meios justificassem os fins. $\mathrm{O}$ direito à alfabetização envolve a ação alfabetizadora plena que garanta aos estudantes o acesso ao mundo letrado e proporcione condições para compreender e participar das transformações que podem ocorrer em sociedade (Frade, 20I9).

Ao considerar que a alfabetização tem, também, a função de transformação social, ressalta-se que o programa Tempo de Aprender (Brasil, 2020), como parte da Política Nacional de Alfabetização, induz a performatividade docente, uma vez que, o trabalho do professor será constantemente monitorado por meio de um conjunto de políticas de metas, prescrição de materiais didáticos e avaliações. Nesse caso, as exigências colocadas pelo programa coadunam com o que Ball $(2002$, p. 5$)$ conceitua de performatividade: «[...] uma tecnologia, uma cultura e um modo de regulação, que se serve de críticas, comparações e exposições como meios de controle, atrito e mudança».

Percebe-se que no referido programa, professores estarão subordinados à lógica que estimula a produtividade, competitividade e limita a educação à busca por resul- 
ANÁLISE SOBRE O PROGRAMA TEMPO DE APRENDER NO BRASIL:

O DIREITO À ALFABETIZAÇÃO OU A PERFORMATIVIDADE DOCENTE?

L. AMARANTE, J. ALVES DA SILVA MOREIRA E L. DORNELES GONÇALVES

tados, ou seja, às identidades docentes configuradas para atender medições estatísticas pré-estabelecidas, passíveis de verificação em testes e avaliações alheias ao trabalho docente. De certa forma, isto significa a incorporação de aspectos gerenciais e meritocráticos, próprios do mundo privado, administrada pelo Estado sobre as práticas docentes, como está expresso no programa em tela:

Art. 48. A União instituirá, na forma de normativo próprio, uma premiação para professores e gestores escolares cujas unidades participem do Programa Tempo de Aprender e apresentem desempenho satisfatório. (Brasil, 2020, p. 7)

Assim, tomadas em conjunto de avaliações e testes, as premiações escamoteiam as verdadeiras prioridades da alfabetização e sua relevância para a sociedade é minimizada. Ao que passa a premiar, a política acaba por determinar o perfil do docente e orientar seu trabalho com vistas ao alcance de metas projetadas a despeito do trabalho dos professores. Como implicações, a rotina de trabalho com a alfabetização nas escolas públicas brasileiras, tende a pautar-se em ações de melhor performatividade que se fundamentam na meritocracia, competitividade e cumprimento de metas em busca de resultados satisfatórios e melhores índices no ranqueamento das avaliações externas.

Nesse contexto, a performatividade docente induz a uma espécie de accountability do trabalho do professor, tornando-o peça essencial e quase exclusiva das mudanças necessárias para que o estudante se aproprie do processo de aquisição da língua escrita e, assim, regule sua prática por meio da avaliação externa, da entrega de resultados e responsabilização. Por accountability, considere-se a «[...] resultante da interação de três dimensões essenciais: avaliação, prestação de contas e responsabilização» (Afonso, 2019, p. 07).

O programa Tempo de Aprender (Brasil, 2020) agrega tais caracterizações e, por isso, demonstra incapacidade em seus objetivos para atuar como uma política de Estado capaz de atender a garantia do direito à alfabetização. Suas proposições constituem o trabalho docente na alfabetização como mais um esforço para constituir um professor gerencial, atrelado a princípios mercadológicos, capaz de lidar com metas, avaliações e entrega de resultados de aprendizagem, o que, em síntese, é a negação do esforço pautado no direito a todos estar alfabetizados, uma vez que, nomeadamente, «o direito à educação é, concretamente, um direito humano» (Cara, 20ı9, p. 26).

De outra forma, a conformação do trabalho docente alfabetizador em um sistema regulatório, como parece se apresentar no Tempo de Aprender (Brasil, 2020), contribui para expropriar dos professores a capacidade intelectiva própria da atividade docente, a qual busca, no processo educativo, a articulação das dimensões formativas ao processo de alfabetização. $\mathrm{Na}$ medida em que professores se tornam robotizados por mecanismo externos e tangentes ao seu trabalho, ao saber produzido da prática, a política acaba por negar o direito de aprendizagem e, assim, o direito à educação.

A responsabilização exclusiva do professor, por meio de instrumentos próprios do mercado privado, para que atinja um determinado resultado, figura em um caminho injusto que desvaloriza a profissão de professor, pois, é preciso considerar a complexidade do processo escolarizado, muitas vezes marcado pela negação das condições que antecedem, mas são fundamentais ao processo. 

ANÁLISE SOBRE O PROGRAMA TEMPO DE APRENDER NO BRASIL:
O DIREITO À ALFABETIZAÇÃO OU A PERFORMATIVIDADE DOCENTE?
L. AMARANTE, J. ALVES DA SILVA MOREIRA E L. DORNELES GONÇALVES

\section{Limites e possibilidades dos docentes no contexto do programa Tempo de Aprender}

Ao instituir o programa Tempo de Aprender (Brasil, 2020) com diretrizes para melhoria da aprendizagem da leitura e da escrita, algumas inquietações em relação aos limites e possibilidades, preocupam, sobretudo no que se refere à garantia do direito à alfabetização.

Em primeiro lugar, salienta-se que até a presente data ${ }^{7}$ este programa encontra-se em fase de apresentação às redes e sistemas de ensino, todavia, sem discussão coletiva prévia acerca das necessidades e urgências da escola pública, tendo como parâmetro, apenas, os resultados obtidos em avaliações externas. Aqueles municípios que adotarem o programa Tempo de Aprender, deverão incorporar suas metas e introduzir uma proposta de formação de professores via plataforma digital.

Um segundo limite diz respeito à individualização do docente para que tome conhecimento e faça as devidas reformulações e adaptações das diretrizes recomendadas no programa. Como tem sido a tônica de políticas no campo da educação básica, fica a cargo do professor, a despeito de precária formação ofertada pelo programa, a execução da política, cabendo a ele, portanto, a responsabilidade dos seus resultados. Nesse sentido concorda-se com Freitas (2018) quando afirma ser possível uma nova educação participativa e democrática.

Temos que abrir espaço para pensarmos a educação com outra concepção, que nos permita exercitar uma responsabilização horizontalizada e participativa, na qual estudantes, professores, pais e gestores em todos os níveis se abram para uma gestão democática da escola, com a perspectiva de uma escola pública de gestão pública. (Freitas, 20I8, pp. I29-I30)

De outro modo, ressalta-se que algumas possibilidades merecem ser intensificadas, a fim de reinterpretar os limites nas determinações apresentadas pelo programa Tempo de Aprender (Brasil, 2020). É preciso lembrar que, no âmbito das políticas, o contexto da prática é o cenário das possibilidades, alternativas e mudanças de rumos. Nesse sentido, Ball (200I) argumenta que o contexto da prática possibilita que uma nova política produza efeitos e consequências que podem se constituir em transformações na política original. Ao implementar o programa, o mesmo pode ser reinterpretado e transformado no contexto da prática tendo o professor uma função importante nessas novas configurações e nos diversos significados que podem ser atribuídos aos textos produzidos.

A maior parte das políticas são frágeis, produto de acordos, algo que pode ou não funcionar; elas são retrabalhadas, aperfeiçoadas, ensaiadas, crivadas de nuances e moduladas através de complexos processos de influência, produção e disseminação de textos e, em última análise, recriadas nos contextos da prática. (Ball, 200I, p. IO2)

Referimos-nos ao primeiro semestre de 2020, onde o mundo vivenciou uma crise sanitária em virtude da pandemia pela Covid-I9, o que levou os países a seguirem as recomendações da Organização Mundial da Saúde (OMS). Nesse conturbado contexto, as reformas educacionais curriculares que estavam em andamento nos sistemas de ensino do Brasil ficaram paralisadas para atendimento das reformas emergenciais pautadas no isolamento social para conter a proliferação do vírus no país. 
ANÁLISE SOBRE O PROGRAMA TEMPO DE APRENDER NO BRASIL:

O DIREITO À ALFABETIZAÇÃO OU A PERFORMATIVIDADE DOCENTE?

L. AMARANTE, J. ALVES DA SILVA MOREIRA E L. DORNELES GONÇALVES

Ao analisar as proposições apresentadas no documento de lançamento do Programa Tempo de Aprender (Brasil, 2020) foi possível sintetizar uma análise comparativa sobre os limites e possibilidades da proposta. Todavia, é preciso afirmar que toda política educacional pode ser ressignificada no contexto da prática escolar.

Limites e possibilidades do Programa Tempo de Aprender

\begin{tabular}{|l|l|}
\hline \multicolumn{2}{|l|}{ Portaria 280/2020-Programa Tempo de Aprender } \\
\hline Limites & Possibilidades \\
\hline $\begin{array}{l}\text { Instituição do programa sem a } \\
\text { participação efetiva dos docentes. }\end{array}$ & $\begin{array}{l}\text { Adequação das diretrizes por meio da indissociabilida- } \\
\text { de teórico-prática. }\end{array}$ \\
\hline $\begin{array}{l}\text { Formação para docentes via edu- } \\
\text { cação à distância e por meio de } \\
\text { multiplicadores. }\end{array}$ & $\begin{array}{l}\text { Aprofundar os estudos em hora atividade e em for- } \\
\text { mação continuada relacionando a temáticas pertinentes } \\
\text { e cabíveis às escolas. }\end{array}$ \\
\hline $\begin{array}{l}\text { Assistentes de alfabetização sem } \\
\text { critérios definidos. }\end{array}$ & $\begin{array}{l}\text { Participação das discussões junto às coordenações das } \\
\text { redes e sistemas de ensino para que o assistente também } \\
\text { possa ter formação de qualidade. } \\
\text { Planejamento e orientação em âmbito escolar das ações } \\
\text { do assistente de alfabetização com vistas a auxiliar o alu- } \\
\text { no nas aprendizagens. }\end{array}$ \\
\hline Avaliação e monitoramento. & $\begin{array}{l}\text { Promover, de acordo com conteúdos científicos, uma } \\
\text { avaliação diagnóstica, recuperativa e não punitiva capaz } \\
\text { de redirecionar o processo de ensino dos estudantes. }\end{array}$ \\
\hline $\begin{array}{l}\text { Premiação de professores atrelada } \\
\text { aos bons resultados. }\end{array}$ & $\begin{array}{l}\text { Participar efetivamente da elaboração das políticas que } \\
\text { envolvem a valorização digna dos docentes sem crité- } \\
\text { rios meritocráticos. }\end{array}$ \\
\hline
\end{tabular}

Fonte: Elaborado pelos autores com base na Portaria n. ${ }^{\circ}$ 280/2020 (Brasil, 2020).

O quadro sintetiza as principais diretrizes encontradas na Portaria n. ${ }^{\circ} 280 / 2020$ (Brasil, 2020) sob forma de limites e, ao mesmo tempo, possibilita a observação atenta do que é possível se realizar na alfabetização, em específico, no contexto da prática para alcançar o direito à alfabetização dos estudantes e garantir de forma mais ampla, seu direito à educação.

Como afirmam Bowe, Ball e Gold (1992, p. 2I) «[...] as políticas são intervenções que carregam limitações e possibilidades, e as respostas a essas intervenções acontecem no contexto da prática, para quais as políticas são endereçadas». Portanto, compreende-se que mesmo diante de um programa cujos traços são acentuadamente mercadológicos, a prática docente engendra em si e pode encontrar possibilidades necessárias à garantia do direito à alfabetização, por meio de uma organização didático-pedagógica pautada na democracia e na participação. 
ANÁLISE SOBRE O PROGRAMA TEMPO DE APRENDER NO BRASIL:

\section{Considerações finais}

A partir do estudo, pode-se perceber que entre as prioridades do governo Bolsonaro (2019-atualmente) e do programa Tempo de Aprender (Brasil, 2020) está à promoção da competitividade como condição para elevação dos índices da alfabetização e, consequentemente, a conformação performática da prática docente sob a lógica gerencialista.

Além disso, a introdução do programa junto às redes de ensino no Brasil denota uma espécie de pragmatismo por parte da política, uma vez que investe em uma lógica simplista em busca de resultados, como expressão de incentivos individuais por metas. Nessa linha, o desempenho do trabalho docente no ciclo de alfabetização se torna resultante de um conjunto de parâmetros nivelados apenas pelas metas a serem cumpridas. Depreende-se, assim, que a qualidade da alfabetização está no alcance de seus melhores resultados numéricos e não, necessariamente, no processo construído e, principalmente, nas condições objetivas para a realização da alfabetização.

De outra forma, a centralidade do trabalho docente ganha destaque, na medida em a sua prática, orientada por metas produzidas a despeito de tais condições, induzem um tipo a priori de professores alfabetizadores. Estes, por sua vez, devem enquadrar sua atuação em sala de aula de acordo com as orientações do programa, relegando o caráter intelectivo da docência, sobretudo no campo da alfabetização.

Portanto, compreende-se que a focalização mecanizada entre a prática docente e o desempenho almejado pelo programa Tempo de Aprender (Brasil, 2020) induz um tipo de performatividade do trabalho dos professores que esconde sua dimensão crítica, criativa e intelectual. Dessa forma, torna-se incapaz de possibilitar processos de alfabetização específicos para contextos e necessidades específicas, o que acaba por negar do direito a alfabetização e, por conseguinte, o direito à educação.

Assim, reitera-se a necessidade urgente para a resistência coletiva a programas que induzem às desigualdades sociais impregnadas por uma política neoliberal e ultraconservadora a fim de defender a escola pública, laica, diversa e gratuita.

\section{Bibliografia}

Afonso, A. J. (20I9). A propósito de políticas de accountability em educação: leituras outras em torno de um projeto de pesquisa. In M. P. Schneider e E. L. NArdi, Políticas de accountability em educação: perspectivas sobre avaliação, prestação de contas e responsabilização (pp. 07-I5). Ijuí: Ed. Uníjui.

BALL, S. (200I). Diretrizes políticas globais e relações políticas locais em Educação. Currículo sem Fronteiras, $I(2)$, 99-II6, jul./dez.

BALL, S. (2002). Reformar escolas, reformar professores e os terrores da performatividade. Revista Portuguesa de Educação, I5(2), 3-23. Universidade do Minho: Braga, Portugal.

Bowe, R.; BALL, S. e Gold, A. (1992). Reforming education E changing schools: case studies in policy sociology. London: Routledge.

Brasil. (1998). Constituição da República Federativa do Brasil. Brasília, DF: Senado Federal.

Brasil. (20I8). Relatório SAeb/ANA 20I6: Panorama do Brasil e dos estados. Brasília: Instituto Nacional de Estudos e Pesquisas Educacionais Anísio Teixeira.

Brasil. (2020). Portaria n. ${ }^{\circ} 280$, de I9 de fevereiro de 2020 - Portaria n. ${ }^{\circ} 280$, de 19 de fevereiro de 2020. DOU - Imprensa Nacional. Publicado em: 21/02/2020 Ed: 37, Seção: I Página: 69. 
ANÁLISE SOBRE O PROGRAMA TEMPO DE APRENDER NO BRASIL:

O DIREITO À ALFABETIZAÇÃO OU A PERFORMATIVIDADE DOCENTE?

L. AMARANTE, J. ALVES DA SILVA MOREIRA E L. DORNELES GONÇALVES

CAgliari, L. C. (1989). Alfabetização e Linguística. São Paulo: Scipione.

CARA, D. (20I9). Contra a barbárie, o direito à educação. In F. CAssio (org.), Educação contra a barbárie: por escolas democráticas e pela liberdade de ensinar. . . ed. São Paulo: Boitempo.

Castanheira, S. F. (20I4). Formação de professores: do direito à educação ao direito à aprendizagem. In M. A. Silva e C. da Cunha (orgs.), Educação Básica: Políticas, avanços e pendências. Campinas, SP: Autores Associados.

Filho, L. J. M. e Barros-Mendes, A. das N. N. (2020). Posicionamento da abalf frente ao Programa de Alfabetização "Tempo de Aprender». Universidade do Estado de Santa Catarina. SC, www.abalf.org.br

Frade, I. C. A. da S. (2020). Palavra aberta - BNCC e a alfabetização em duas versões: concepções e desafios. Educação em Revista, 36 . Belo Horizonte. Dossiê Alfabetização e Letramento no Campo Educacional. Ed. 220676.

FreitAs, L. C. de (20I8). A reforma empresarial da educação - nova direita, velhas ideias. I. ${ }^{a}$ ed. São Paulo: Expressão popular.

Gadotti, M. (1982). A Educação contra a educação. São Paulo: Cortez.

Lenardão, E. e Galuch, M. T. B. (20I8). Pedagogia das competências: implicações para a formação docente. In L. H. Nagel, E. J. G. de Carvalho e M. C. G. Machado (orgs.), Bases teóricas e práticas da educação brasileira. Maringá: Eduem.

Mortatti, M. do R. L. (20ıo). Alfabetização no Brasil: conjecturas sobre as relações entre políticas públicas e seus sujeitos privados. Revista Brasileira de Educação, 15 (44), maio/ago.

Mortatti, M. do R. L. (2019). Métodos de alfabetização no Brasil: uma história concisa. São Paulo: Ed. Unesp Digital.

SANTOS, D. (20I7). Educação e precarização profissionalizante: crítica à integração da escola com o mercado. São Paulo: Instituto Lukács.

Saviani, D. (2007). Educação: do senso-comum à consciência filosófica. 17. ${ }^{a}$ ed. Campinas, SP: Autores Associados.

Schneider, G. (20I2). Política educacional e instrumentos de avaliação: pensando um indice de condições materiais da escola. Curitiba: Appris.

Silva, R. e Moreira, J. A. da S. (20I9). A educação, reformas curriculares e as propostas do Banco Mundial no contexto pós-golpe (2016-2018). Colloquium Humanarum, Presidente Prudente, I6(I), I45-I62, jan/mar.

Smolka, A. L. B. (1998). A criança na fase inicial da escrita: a alfabetização como processo discursivo. São Paulo: Cortez; Campinas. UNiCAmP. 
